\title{
MicroRNA-144 affects radiotherapy sensitivity by promoting proliferation, migration and invasion of breast cancer cells
}

\author{
LEI YU, YANMING YANG, JIGUANG HOU, CHENGWEI ZHAI, YUNHAO SONG, \\ ZHILIANG ZHANG, LING QIU and XIAOJING JIA
}

\begin{abstract}
Department of Tumor Radiation Therapy, The Second Hospital of Jilin University, Changchun, Jilin, P.R. China
\end{abstract}
Received May 18, 2015; Accepted June 26, 2015

DOI: 10.3892/or.2015.4173

\begin{abstract}
Radiotherapy resistance remains a major obstacle for patients with breast cancer. miRNAs are important regulators in many biological processes including proliferation, apoptosis, invasion and metastasis and response to treatment in different types of tumors. Here, we describe the role of miRNA-144 in the regulation of radiotherapy sensitivity, migration and invasion of breast cancer cells. The cell survival rate of breast cancer cells was measured by WST-1 assay after irradiation. The caspase-3/-7 activity and apoptotic proteins were analyzed by Caspase-Glo3/7 assay and western blot analysis, respectively. The migration and invasion of breast cancer cells were evaluated by BD Transwell migration and Matrigel invasion assays. The EMT markers were detected by western blot analysis. We found that overexpression of miR-144 increased the proliferation rate of MDA-MB-231 cells without radiation. Both MDA-MB-231 and SKBR3 cells exhibited significantly increased radiation resistance after overexpression of miR-144. Meanwhile, the migration and invasion of both MDA-MB-231 and SKBR3 cells were changed by altered miR-144 expression. In addition, the overexpression of miR-144 inhibited E-cadherin expression and promoted Snail expression. miR-144 activated AKT by downregulation of PTEN in breast cancer cells. Our results strongly suggest that miR-144 acts as an important regulator of tumorigenesis and tumor progression of breast cancer. These results indicate that miR-144 might serve as a potential molecular target for breast cancer treatment.
\end{abstract}

\section{Introduction}

Breast cancer is the leading cause of death from cancer among women both in the developed and the developing world (1).

Correspondence to: Dr Xiaojing Jia, Department of Tumor Radiation Therapy, The Second Hospital of Jilin University, 218 Ziqiang Street, Changchun, Jilin, P.R. China

E-mail: xiaojing.jia@aol.com

Key words: AKT, apoptosis, PTEN, metastasis, miRNA-144, epithelialmesenchymal transition, miRNAs
Approximately 1 in 8 women (12\%) in the United States will develop breast cancer during her lifetime (2). In 2015, $\sim 231,840$ new cases will be diagnosed and $\sim 40,290$ women will die from breast cancer in the United States (3). Radiotherapy is a highly targeted and effective treatment method that uses high-energy rays or particles to inhibit the progression of cancer. Radiation to the breast is often administered after breast-conserving surgery to destroy cancer cells in the breast that may not have been removed during surgery. Radiotherapy reduces the risk of breast cancer recurrence by $70 \%$. However, the development of radioresistance is a significant issue after prolonged exposure in the treatment of breast cancer patients. Cancer stem cells (CSCs) have been identified as the important factor for radioresistance by promoting repair of DNA damage, redistribution of cells in the cell cycle, repopulation, and reoxygenation of hypoxic tumor areas (4-6). In addition, CSCs produce a high level of antioxidant proteins and enhance their reactive oxygen species (ROS) defenses during radiotherapy (7). Recently, Zhang et al found that zinc finger E-box binding homeobox 1 (ZEB1) plays an important role in radioresistance in breast cancer by promoting homologous recombination-dependent DNA repair (8).

miRNAs are a class of small non-coding RNA molecules that regulate the expression of multiple target mRNAs by binding to the 3 '-untranslated region (UTR) $(9,10)$. The pattern of miRNA expression is associated with cancer type, stage and other clinical variables (11). Recently, growing evidence suggests that miRNAs play important roles in the tumorigenesis and progression of breast cancer (12-14). Some miRNAs are found to be upregulated, acting as oncogenes, while some miRNAs are found to be downregulated, acting as tumor-suppressor genes (15). It has been reported that miRNA dysregulation is responsible for the radioresistance in breast tumors. For example, miR-95 is upregulated by ionizing radiation and enhances the proliferation and invasive potential of breast cancer cells by targeting the sphingolipid phosphatase SGPP1 (16). miR-34 may protect breast cancer cells from nonapoptotic cell death (17). Studies have shown that miR-144 is correlated with human disease (18) and modulates metastasis (19).

Here, we examined the roles of miR-144 in breast cancer. We found that overexpression of miR-144 inhibited radiotherapy-induced apoptosis of breast cancer cells. Moreover, miR-144 also enhanced epithelial-mesenchymal transition 
(EMT) of breast cancer cells by activation of PTEN/Akt signaling. Our findings indicate that miR-144 may serve as a potential biomarker to predict the treatment reponse and prognosis of breast cancer and may be utilized as a target for novel therapeutic strategies.

\section{Materials and methods}

Cell lines and culture. The human breast cancer cell lines MDA-MB-231 and SKBR3 were obtained from the American Type Culture Collection (ATCC). MDA-MB-231 and SKBR3 cells were grown in Dulbecco's modified Eagle's medium (DMEM; Invitrogen, USA) supplemented with $10 \%$ heat-inactivated fetal bovine serum (FBS) and $100 \mathrm{U} / \mathrm{ml}$ of penicillin and $100 \mu \mathrm{g} / \mathrm{ml}$ of streptomycin (Sigma-Aldrich, USA). The cells were cultured at $37^{\circ} \mathrm{C}$ in a humidified incubator in an atmosphere of $5 \% \mathrm{CO}_{2}-95 \%$ air.

Cell transfection. miR-144 mimics and anti-miR-144 inhibitor were purchased from GenePharma (Shanghai, China). When breast cancer cells reached $80 \%$ confluency, the miR-144 or anti-miR-144 inhibitor was transfected into cells using Lipofectamine 2000 (Invitrogen) according to the manufacturer's instructions. The scrambled oligonucleotide was chosen as a negative control.

miRNA quantification by quantitative real-time polymerase chain reaction ( $q R T-P C R$ ). To detect miR-144 expression, total RNA was extracted with the mirVana miRNA isolation kit (Ambion, USA) according to the manufacturer's instructions. cDNA was synthesized from the isolated RNA with TaqMan microRNA reverse transcription kit. The PCR conditions were $95^{\circ} \mathrm{C}$ for $5 \mathrm{~min}$, followed by 35 cycles of $95^{\circ} \mathrm{C}$ for $30 \mathrm{sec}$ and $65^{\circ} \mathrm{C}$ for $30 \mathrm{sec}$, and a dissociation stage. PCR was performed using the TaqMan Universal PCR Master Mix and BioRad CFX384 machine. The endogenous reference gene GAPDH was used for RNA quantification. The PCR primer sequences used were: 5'-GTCTCCTCTGACTTCAACAGCG-3' and 5'-ACCACCCTGTTGCTGTAGCCAA-3' (GAPDH).

Cell proliferation assay. Cell proliferation was assessed using the WST-1 assay (Roche, USA). Briefly, breast cancer cells, transfected with the scrambled oligonucleotide or miR-144 mimic, were seeded in triplicate in each well of 24-well plates at the density of $2 \times 10^{4}$ cells/well. After $12 \mathrm{~h}$ of culture, the cells were irradiated with different doses of ionizing radiation. On every other day, $10 \mu \mathrm{l}$ of WST-1 was added to each well, and the plates were incubated for $1.5 \mathrm{~h}$ at $37^{\circ} \mathrm{C}$. Then $100 \mu \mathrm{l}$ WST-1/medium solution was transferred to a 96-well plate. Optical density was measured at 440 (OD440) minus $600 \mathrm{~nm}$ using a microplate spectrophotometer. All experiments were carried out in triplicates.

Analysis of apoptosis. Breast cancer cells, transfected with either the scrambled oligonucleotide or miR-144 mimic, were seeded in 24-well plates at a density of $1 \times 10^{5} /$ well. After $18 \mathrm{~h}$ of incubation in an atmosphere of $5 \% \mathrm{CO}_{2}-95 \%$ air, the breast cancer cells were irradiated with different doses of ionizing radiation. The apoptosis was measured using the Caspase-Glo3/7 assay kit (Promega, Madison, WI, USA) according to the manufacturer's instructions. Briefly, the breast cancer cells were cultured for $36 \mathrm{~h}$ after ionizing radiation, then Caspase-Glo reagent was added to each well and incubated at room temperature for $8 \mathrm{~h}$ with gentle shaking. The luminescence value was measured with a luminometer (Thermo Labsystems) using $1 \mathrm{~min}$ lag time and $0.5 \mathrm{sec} / \mathrm{well}$ read time. The experiments were performed in triplicate.

Matrigel invasion assays. Cell invasion was examined by Matrigel invasion assays according to the manufacturer's instructions. Briefly, breast cancer cells, transfected with either miR-144 mimic or the anti-miR-144 inhibitor, were placed on the upper BD BioCoat Matrigel Invasion Transwell insert (BD Biosciences, USA) in $0.5 \mathrm{ml}$ DMEM with $0.1 \%$ BSA. DMEM containing 5\% FBS was added to the lower chamber. After $24 \mathrm{~h}$, the non-invaded cells were removed with a cotton swab, and the invaded cells were stained by Diff-Quik stain. The invaded cells were counted under microscopy. The percentage of invasion was expressed as the ratio of invading cells over cell number normalized on day 2 of the growth curve.

Cell lysate and western blot analysis. The transfected breast cancer cells were lysed with ice-cold RIPA buffer (Beyotime, China). The cell debris and insoluble material were removed by centrifugation at $4^{\circ} \mathrm{C}$. The cell lysates were mixed with loading buffer and boiled at $100^{\circ} \mathrm{C}$, and then the samples were separated by SDS-PAGE and transferred to polyvinylidene fluoride (PVDF) membranes (Sigma-Aldrich). The membranes were incubated in 5\% non-fat dry milk in Tris-buffered saline Tween-20 buffer (TBST: $10 \mathrm{mmol} / \mathrm{l}$ Tris-base, $150 \mathrm{mmol} / \mathrm{l} \mathrm{NaCl}, 0.05 \%$ Tween-20; $\mathrm{pH} \mathrm{7.4)} \mathrm{for} 1 \mathrm{~h}$ at room temperature to block non-specific antibody binding sites. Then the membranes were incubated overnight at $4^{\circ} \mathrm{C}$ with primary antibodies (N-cadherin, Snail, Slug, vimentin, Twist, caspase-9, Bcl-2, Bax, AKT and PTEN; Cell Signaling Technology, USA) in TBST with gentle agitation. After being washed with TBST, the membranes were incubated with the horseradish peroxidase-conjugated secondary antibody for $1 \mathrm{~h}$ at room temperature. The immune blot signals were visualized using the EasySee Western Blot kit (Transgen, China). The protein bands were detected by densitometric scanning (Tanon-1600 Gel Image System; Tanon, Shanghai, China).

Statistical analysis. Statistical analyses of the above results were performed using the Student's t-test using the SPSS program (version 11.0; SPSS Inc., USA). Differences were considered statistically significant at $\mathrm{p}<0.05$.

\section{Results}

miR-144 promotes the survival of breast cancer cells following irradiation. To examine the effect of miR-144 on radiation resistance in breast cancer cells, miR-144 was transiently transfected into MDA-MB-231 and SKBR3 cells with Lipofectamine 2000, and the cell survival rate was measured by WST-1 assay. As shown in Fig. 1A, we confirmed that the miR-144 expression level was significantly increased in the breast cancer cells using qRT-PCR $(\mathrm{p}<0.01)$. Without radiation, overexpression of miR-144 increased the rate of proliferation of the MDA-MB-231 cells ( $p<0.05$, Fig. 1B) and 
A
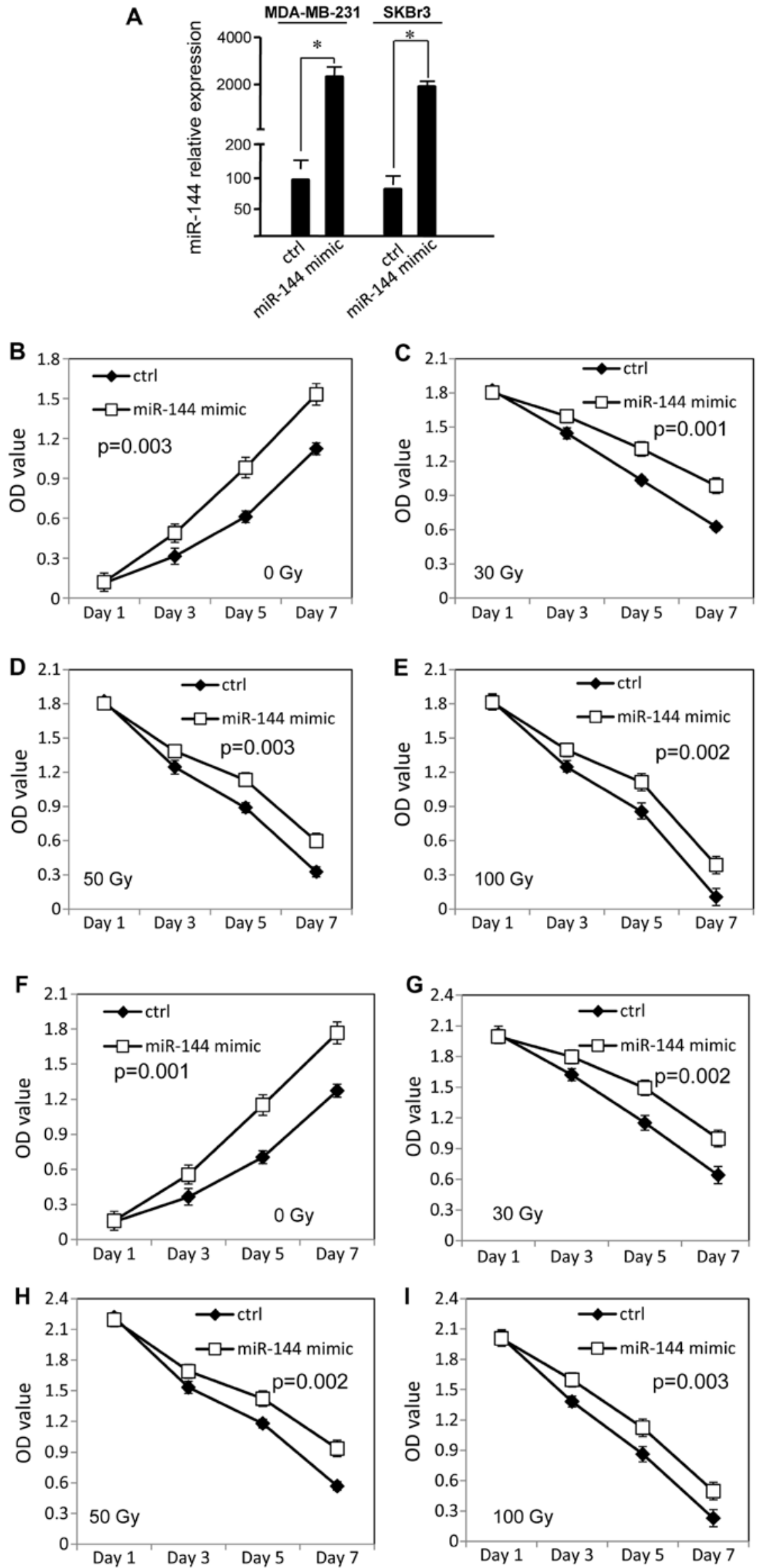

Figure 1. miR-144 promotes the survival of breast cancer cells following irradiation. (A) The miR-144 expression level was examined by qRT-PCR after the transfection of breast cancer cells. (B) The proliferation of MDA-MB-231 cells without irradiation. The proliferation rate of MDA-MB-231 cells with (C) $30 \mathrm{~Gy}$, (D) $50 \mathrm{~Gy}$ and (E) $100 \mathrm{~Gy}$ of irradiation. (F) The proliferation of SKBR3 cells without irradiation. The proliferation rate of SKBR3 cells with (G) $30 \mathrm{~Gy},(\mathrm{H}) 50 \mathrm{~Gy}$ and (I) $100 \mathrm{~Gy}$ of irradiation. 

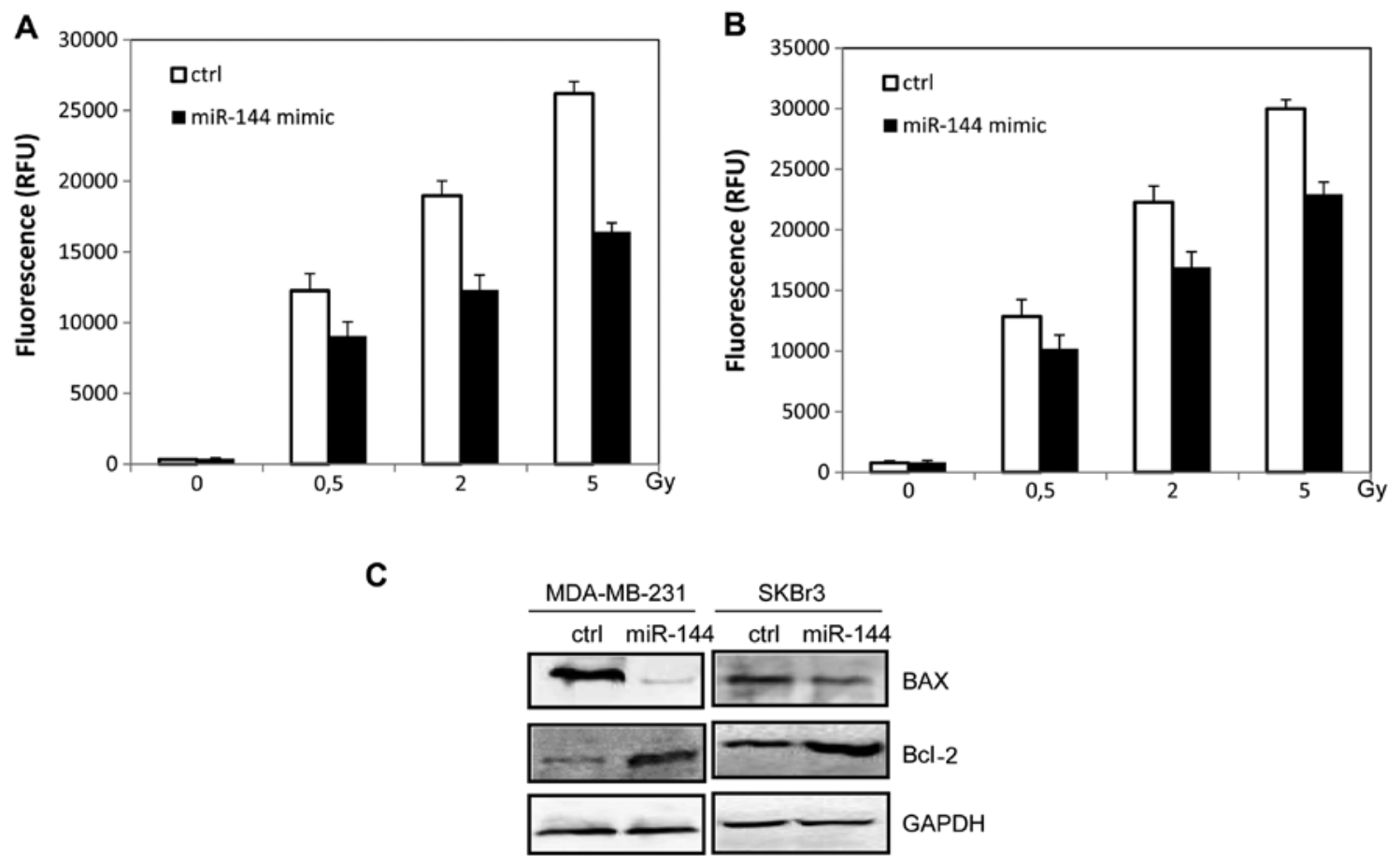

Figure 2. miR-144 inhibits radiation-induced apoptosis in breast cancer cells. (A) The caspase-3/-7 activity was decreased in the MDA-MB-231 cells transfected with miR-144. (B) The caspase-3/-7 activity was decreased in SKBR3 cells transfected with miR-144. (C) The levels of apoptotic proteins in MDA-MB-231 and SKBR3 cells transfection with the miR-144 mimic after irradiation.

SKBR3 cells ( $\mathrm{p}<0.05$, Fig. 1F), as compared with the negative control. The MDA-MB-231 cells displayed significantly increased radiation resistance after overexpression of miR-144, as compared with the control cells ( $p<0.05$, Fig. 1C-E). The miR-144 mimic-transfected SKBR3 cells also exhibited increased radiation resistance $(\mathrm{p}<0.05$, Fig. 1G-I).

miR-144 inhibits radiation-induced apoptosis in breast cancer cells. We further examined the effect of miR-144 on radiation resistance by apoptosis analysis. The miR-144 mimic was transiently transfected into MDA-MB-231 and SKBR3 cells with Lipofectamine 2000. Then the cells were irradiated followed by analysis of caspase-3/-7 activity. The expression of apoptotic proteins was evaluated by western blot analysis. We found that overexpression of miR-144 reduced the sensitivity of breast cancer cells to the effects of irradiation by inhibiting caspase-3/-7 activities ( $<<0.05$, Fig. $2 \mathrm{~A}$ and B). As shown in Fig. $2 \mathrm{C}$, the ability of irradiation to increase BAX and caspase-9 expression was inhibited as a result of miR-144 overexpression $(\mathrm{p}<0.05)$. The Bcl-2 expression was also increased in the miR-144-overexpressing cells ( $\mathrm{p}<0.05$, Fig. 2C).

miR-144 promotes migration and invasion in breast cancer cells. To further investigate the effect of miR-144 on cell aggression, we examined the effect of miR-144 on migration and invasion of breast cancer cells with Transwell migration and Matrigel invasion assays. As shown in Fig. 3A-D, the migration and invasion of the MDA-231 cells were enhanced after transfection with the miR-144 mimic. The same effects were observed in another breast cancer cell line SKBR3 ( $p<0.05$, Fig. 3I-L). In contrast, migration and invasion were decreased with anti-miR-144 inhibitor treat- ment in the MDA-231 cells ( $<<0.05$, Fig. 3E-H) and SKBR3 cells $(\mathrm{p}<0.05$, Fig. 3M-P).

miR-144 affects the expression of EMT proteins and activates $A K T$ in breast cancer cells. We next determined expression of EMT markers by western blot analysis after breast cancer cells were transfected with either the miR-144 mimic or the anti-miR-144 inhibitor. Expression of N-cadherin, vimentin and Snail was increased after breast cancer cells were transfected with the miR-144 mimic (Fig. 4A). In contrast, decreased $\mathrm{N}$-cadherin, vimentin and Snail was observed in the breast cancer cells transfected with the anti-miR-144 inhibitor (Fig. 4B). We further found that the expression of AKT was increased, and the PTEN expression level was decreased in the breast cancer cells after transfection with the miR-144 mimic (Fig. 5A). As shown in Fig. 5B, the transfection with anti-miR-144 inhibitor decreased the AKT protein level and increased PTEN expression in the breast cancer cells.

\section{Discussion}

Although the 5-year survival rate of breast cancer patients has been markedly improved due to early diagnosis and effect of treatment, the development of radiotherapy resistance is a significant issue in the treatment of breast cancer patients $(20,21)$. Studies have shown that the development of radiotherapy resistance correlates with various signaling pathways that regulate cell survival, proliferation and apoptosis. For example, Tessner et al found that prostaglandin E2 inhibited radiation-induced apoptosis by activation of AKT and BAX translocation (22). Zhang et al found that protein ZEB1 promotes radioresistance in breast cancer by regulating 

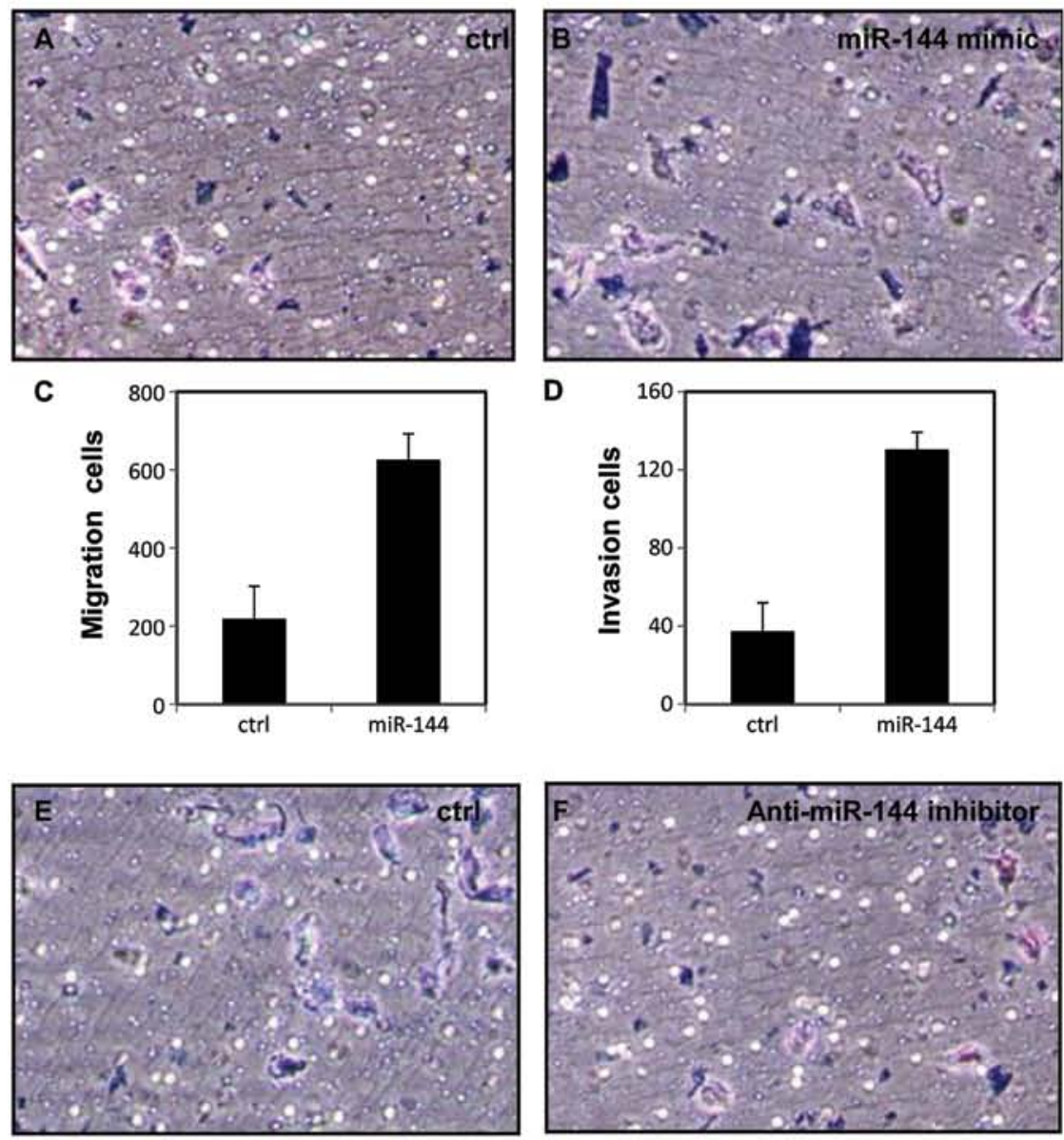

G
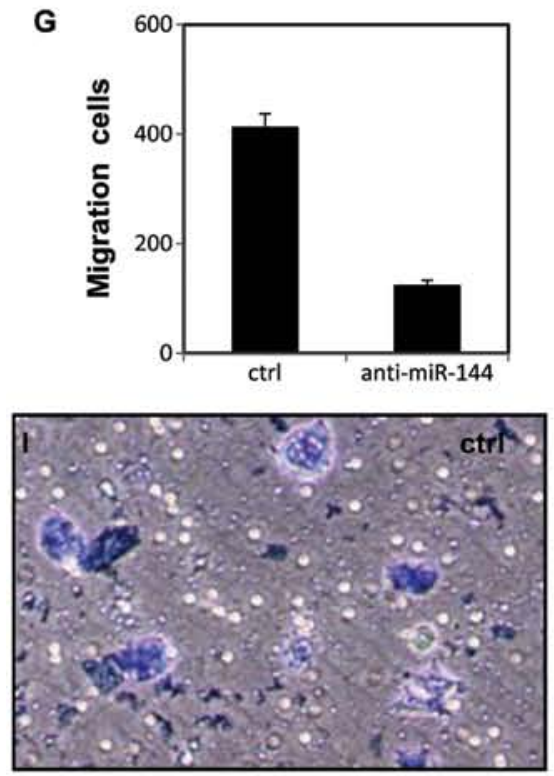

K

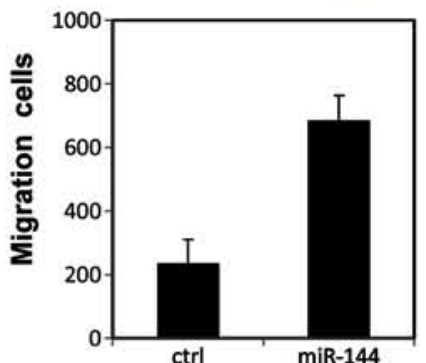

H
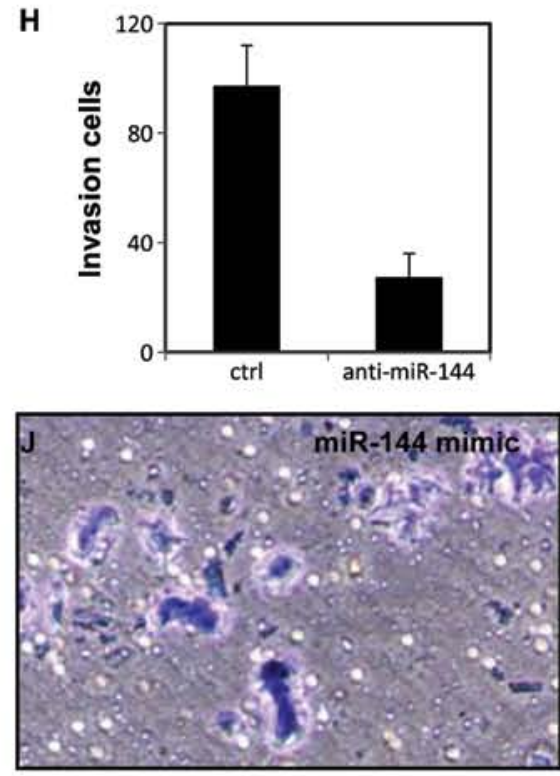

L

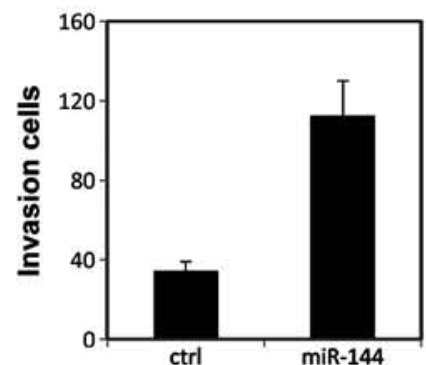

Figure 3. miR-144 increases the migration and invasion of breast cancer cells. (A-D) The migration and invasion of MDA-MB-231 cells were increased after transfection with the miR-144 mimic. (E-H) The migration and invasion of the MDA-MB-231 cells were decreased after transfection with the anti-miR-144 inhibitor. (I-L) The migration and invasion of SKBR3 cells were increased after transfection with the miR-144 mimic. 

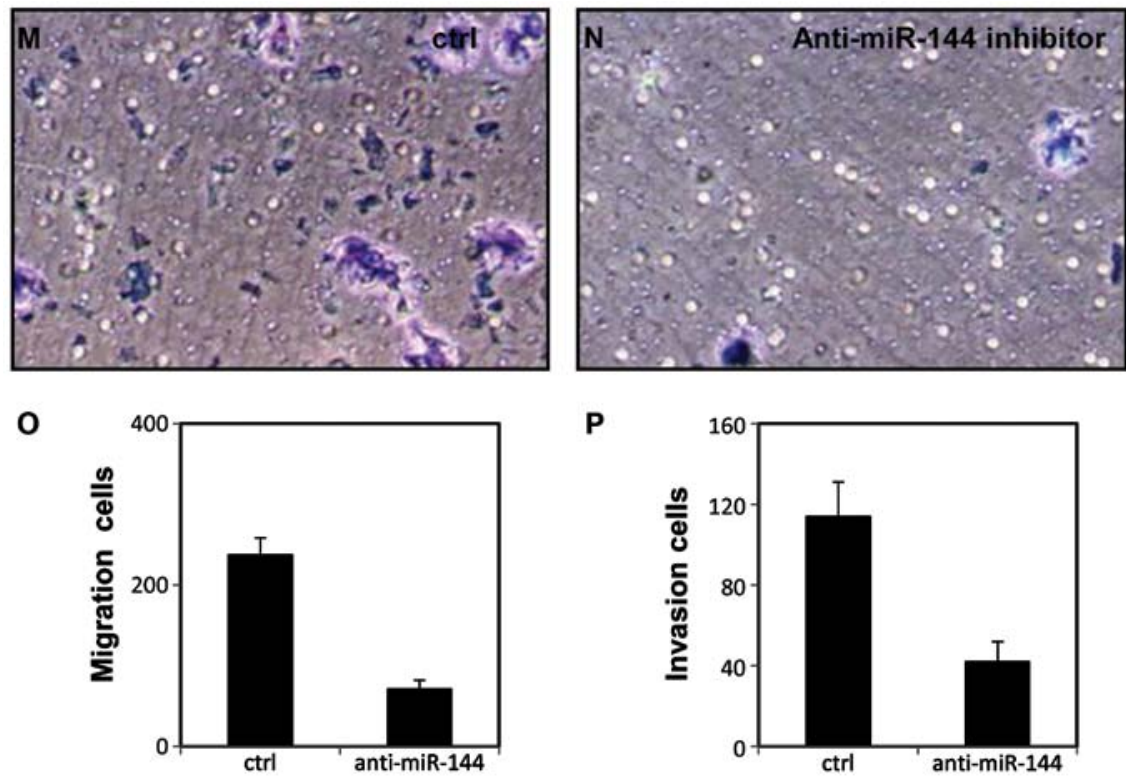

Figure 3. Continued. miR-144 increases the migration and invasion of breast cancer cells. (M-P) The migration and invasion of the SKBR3 cells were decreased after transfection with the anti-miR-144 inhibitor. All experiments were performed three times in triplicate.

A

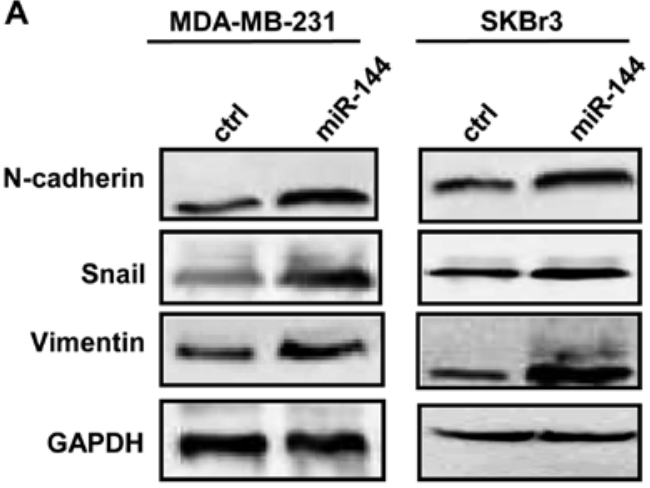

B

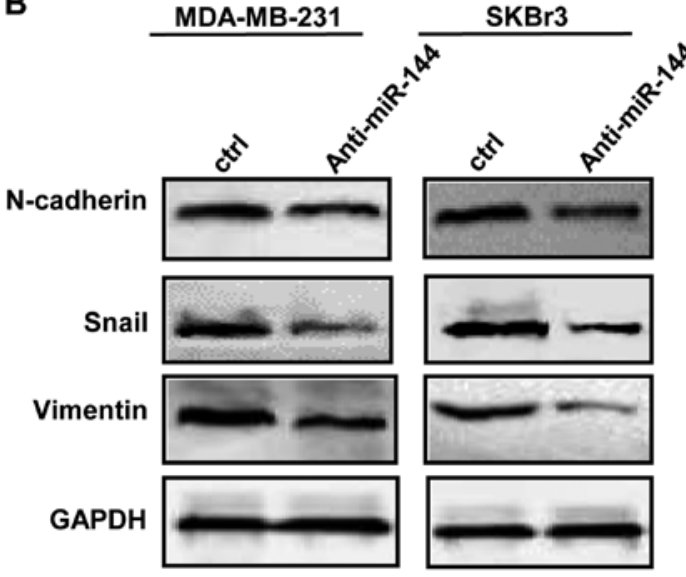

Figure 4. miR-144 regulates expression of EMT markers in breast cancer cells. (A) The levels of EMT markers in the breast cancer cells after transfection with the miR-144 mimic. (B) The levels of EMT markers in the breast cancer cells after transfection with the anti-miR-144 inhibitor. EMT, epithelial-mesenchymal transition.
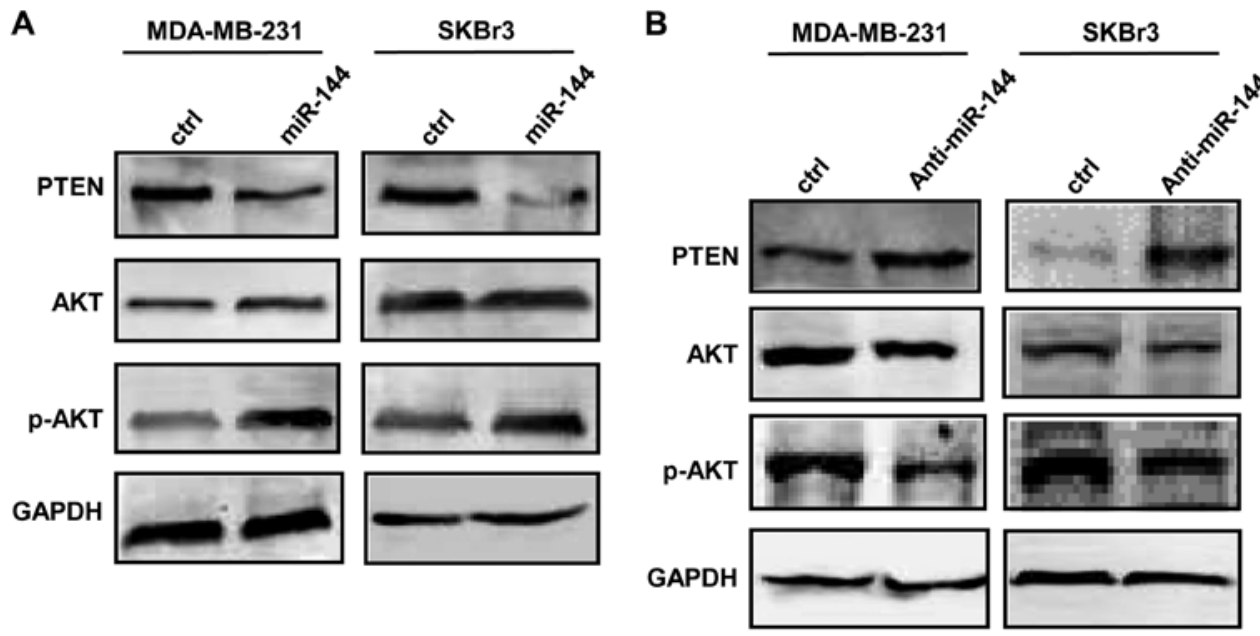

Figure 5. miR-144 inhibits PTEN and activates AKT in the breast cancer cells. (A) Expression of AKT and PTEN in breast cancer cells after transfection with the miR-144 mimic. (B) The expression of PTEN and AKT in breast cancer cells after transfection with the anti-miR-144 inhibitor. 
homologous recombination-dependent DNA repair (8). Cellular response to ionizing radiation activates signaling pathways mediating the DNA damage response. Growing evidence has demonstrated that miRNAs are involved in the regulation of the DNA damage response (23). Aberrant expression of miR-144 has been found in many different human cancers. Iwaya et al found that downregulation of miR-144 could predict the poor prognosis of colorectal cancer patients by activation of the mTOR signaling pathway (24). Guo et al reported that miR-144 could regulate proliferation in bladder cancer cells by targeting enhancer of zeste homolog 2 (EZH2) (25).

Buffa et al found that a high level of miR-144 is associated with poor prognosis in breast cancer (26). In our study, we found that miR-144 increased the rate of proliferation of MDA-MB231 and SKBR3 cells. Moreover, both MDA-MB-231 and SKBR3 cells displayed significantly increased radiation resistance after overexpression of miR-144. Our results indicate that miR-144 may play an important role in the radiation resistance of breast cancer cells.

Invasion and metastasis of aggressive breast cancer cells are the final and fatal step during cancer progression (27). Metastasis is an extremely complicated multistep pathophysiological process involving intravasation, survival in circulation, extravasation, and colonization and growth at a distant site (28). EMT is an important process during the metastasis of cancer cells. EMT is a biological process that allows a polarized epithelial cell to acquire a mesenchymal cell phenotype. These changes enhance the migratory capacity, invasiveness, and elevated resistance to apoptosis and are associated with the high aggressiveness or recurrence of tumors (29). Commonly used molecular markers for EMT include E-cadherin, N-cadherin, Snail and vimentin (30). Here, we showed that miR-144 enhanced the migration and invasion of MDA-MB-231 and SKBR3 cells after overexpression of miR-144. In contrast, the migration and invasion of MDA-MB231 and SKBR3 cells were decreased when breast cancer cells were treated with the anti-miR-144 inhibitor. Moreover, we found that the expression level of EMT biomarkers was altered in breast cancer cells with aberrant expression of miR-144. These results indicate that miR-144 plays important roles in breast cancer progression.

PTEN, a tumor-suppressor gene, plays important roles in the regulation of tumor cell growth, cell cycle, apoptosis, invasion and metastasis (31). The loss or mutation of PTEN in many primary and metastatic human cancers leads to activation of the phosphoinositide-3-kinase (PI3K)-PKB/Akt signaling pathway (32). Studies have demonstrated that PTEN is important for breast cancer development and prognosis $(33,34)$. Recent studies have shown that PTEN signaling plays roles in EMT and metastasis (35). Growing evidence has shown that miRNAs play critical roles in the regulation of tumor development, progression and prognosis by directly targeting the PTEN/Akt signaling pathway $(36,37)$. In the present study, we found that miR-144 decreased the expression of PTEN and increased the expression of pAKT in the MDA-MB-231 and SKBR3 cells. These results indicate that the PTEN/Akt signaling pathway may be targeted by miR-144 in breast cancer. miR-144 plays important roles in breast cancer and radiotherapy resistance through the PTEN/Akt signaling pathway.
In summary, miR-144 plays important roles in the regulation of tumorigenesis and malignant progression in breast cancer. miR-144 may be a potential molecular target in breast cancer treatment in the future.

\section{References}

1. Siegel R, Ma J, Zou Z and Jemal A: Cancer statistics, 2014. CA Cancer J Clin 64: 9-29, 2014.

2. Donepudi MS, Kondapalli K, Amos SJ and Venkanteshan P: Breast cancer statistics and markers. J Cancer Res Ther 10: 506-511, 2014.

3. Abels JC, Gorham AT, Pack GT and Rhoads CP: Metabolic studies in patients with cancer of the gastro-intestinal tract. I. Plasma vitamin A levels in patients with malignant neoplastic disease, particularly of the gastro-intestinal tract. J Clin Invest 20: 749-764, 1941.

4. Peitzsch C, Kurth I, Kunz-Schughart L, Baumann M and Dubrovska A: Discovery of the cancer stem cell related determinants of radioresistance. Radiother Oncol 108: 378-387, 2013.

5. Rich JN: Cancer stem cells in radiation resistance. Cancer Res 67: 8980-8984, 2007.

6. Pajonk F, Vlashi E and McBride WH: Radiation resistance of cancer stem cells: The 4 R's of radiobiology revisited. Stem Cells 28: 639-648, 2010.

7. Diehn M, Cho RW, Lobo NA, Kalisky T, Dorie MJ, Kulp AN, Qian D, Lam JS, Ailles LE, Wong M, et al: Association of reactive oxygen species levels and radioresistance in cancer stem cells. Nature 458: 780-783, 2009.

8. Zhang P, Wei Y, Wang L, Debeb BG, Yuan Y, Zhang J, Yuan J, Wang M, Chen D, Sun Y, et al: ATM-mediated stabilization of ZEB1 promotes DNA damage response and radioresistance through CHK1. Nat Cell Biol 16: 864-875, 2014.

9. Manikandan J, Aarthi JJ, Kumar SD and Pushparaj PN: OncomiRs: The potential role of non-coding microRNAs in understanding cancer. Bioinformation 2: 330-334, 2008.

10. Esquela-Kerscher A and Slack FJ: OncomiRs - microRNAs with a role in cancer. Nat Rev Cancer 6: 259-269, 2006.

11. Lee YS and Dutta A: MicroRNAs in cancer. Annu Rev Pathol 4: 199-227, 2009.

12. Nana-Sinkam SP and Croce CM: MicroRNA regulation of tumorigenesis, cancer progression and interpatient heterogeneity: Towards clinical use. Genome Biol 15: 445, 2014.

13. Zhou W, Shi G, Zhang Q, Wu Q,Li B and ZhangZ: MicroRNA-20b promotes cell growth of breast cancer cells partly via targeting phosphatase and tensin homologue (PTEN). Cell Biosci 4: 62, 2014.

14. Li L, Xiao B, Tong H, Xie F, Zhang Z and Xiao GG: Regulation of breast cancer tumorigenesis and metastasis by miRNAs. Expert Rev Proteomics 9: 615-625, 2012.

15. Zhang B, Pan X, Cobb GP and Anderson TA: microRNAs as oncogenes and tumor suppressors. Dev Biol 302: 1-12, 2007.

16. Huang X, Taeb S, Jahangiri S, Emmenegger U, Tran E, Bruce J, Mesci A, Korpela E, Vesprini D, Wong CS, et al: miRNA-95 mediates radioresistance in tumors by targeting the sphingolipid phosphatase SGPP1. Cancer Res 73: 6972-6986, 2013.

17. Kato M, Paranjape T, Müller RU, Nallur S, Gillespie E, Keane K, Esquela-Kerscher A, Weidhaas JB and Slack FJ: The miR-34 microRNA is required for the DNA damage response in vivo in C. elegans and in vitro in human breast cancer cells. Oncogene 28: 2419-2424, 2009.

18. Keller A, Leidinger P, Vogel B, Backes C, ElSharawy A, Galata V, Mueller SC, Marquart S, Schrauder MG, Strick R, et al: miRNAs can be generally associated with human pathologies as exemplified for miR-144. BMC Med 12: 224, 2014.

19. Zhang J, Qin X, Sun Q, Guo H, Wu X, Xie F, Xu Q, Yan M, Liu J, Han Z, et al: Transcriptional control of PAX4-regulated miR-144/451 modulates metastasis by suppressing ADAMs expression. Oncogene 34: 3283-3295, 2015.

20. DeSantis CE, Lin CC, Mariotto AB, Siegel RL, Stein KD, Kramer JL, Alteri R, Robbins AS and Jemal A: Cancer treatment and survivorship statistics, 2014. CA Cancer J Clin 64: 252-271, 2014.

21. Nakshatri H: Radiation resistance in breast cancer: Are CD $44^{+} / \mathrm{CD} 24 \%$ proteosome low/PKH26 ${ }^{+}$cells to blame? Breast Cancer Res 12: 105, 2010 
22. Tessner TG, Muhale F, Riehl TE, Anant S and Stenson WF Prostaglandin E2 reduces radiation-induced epithelial apoptosis through a mechanism involving AKT activation and bax translocation. J Clin Invest 114: 1676-1685, 2004.

23. Cellini F, Morganti AG, Genovesi D, Silvestris N and Valentini V: Role of microRNA in response to ionizing radiations: Evidences and potential impact on clinical practice for radiotherapy. Molecules 19: 5379-5401, 2014.

24. Iwaya T, Yokobori T, Nishida N, Kogo R, Sudo T, Tanaka F, Shibata K, Sawada G, Takahashi Y, Ishibashi M, et al: Downregulation of miR-144 is associated with colorectal cancer progression via activation of mTOR signaling pathway. Carcinogenesis 33: 2391-2397, 2012

25. Guo Y, Ying L, Tian Y, Yang P, Zhu Y, Wang Z, Qiu F and Lin J: miR-144 downregulation increases bladder cancer cell proliferation by targeting EZH2 and regulating Wnt signaling. FEBS J 280: 4531-4538, 2013.

26. Buffa FM, Camps C, Winchester L, Snell CE, Gee HE, Sheldon H, Taylor M, Harris AL and Ragoussis J: microRNA-associated progression pathways and potential therapeutic targets identified by integrated mRNA and microRNA expression profiling in breast cancer. Cancer Res 71: 5635-5645, 2011.

27. McAllister SD, Murase R, Christian RT, Lau D, Zielinski AJ, Allison J, Almanza C, Pakdel A, Lee J, Limbad C, et al: Pathways mediating the effects of cannabidiol on the reduction of breast cancer cell proliferation, invasion, and metastasis. Breast Cancer Res Treat 129: 37-47, 2011.

28. Webb CP and Vande Woude GF: Genes that regulate metastasis and angiogenesis. J Neurooncol 50: 71-87, 2000.

29. Kalluri R and Neilson EG: Epithelial-mesenchymal transition and its implications for fibrosis. J Clin Invest 112: 1776-1784, 2003.
30. Lee JM, Dedhar S, Kalluri R and Thompson EW: The epithelial-mesenchymal transition: New insights in signaling, development, and disease. J Cell Biol 172: 973-981, 2006.

31. Liang WT, Cheng ZY, Jia ZQ and Wang BY: PTEN: A new target in inhibiting of tumor invasion and metastasis. Sheng Li Ke Xue Jin Zhan 42: 201-205, 2011 (In Chinese).

32. Carracedo A and Pandolfi PP: The PTEN-PI3K pathway: Of feedbacks and cross-talks. Oncogene 27: 5527-5541, 2008.

33. Hühns M, Salem T, Schneider B, Krohn M, Linnebacher M and Prall F: PTEN mutation, loss of heterozygosity, promoter methylation and expression in colorectal carcinoma: Two hits on the gene? Oncol Rep 31: 2236-2244, 2014.

34. Kechagioglou P, Papi RM, Provatopoulou X, Kalogera E, Papadimitriou E, Grigoropoulos P, Nonni A, Zografos G, Kyriakidis DA and Gounaris A: Tumor suppressor PTEN in breast cancer: Heterozygosity, mutations and protein expression. Anticancer Res 34: 1387-1400, 2014.

35. Mulholland DJ, Kobayashi N, Ruscetti M, Zhi A, Tran LM, Huang J, Gleave $\mathrm{M}$ and $\mathrm{Wu} \mathrm{H}$ : Pten loss and RAS/MAPK activation cooperate to promote EMT and metastasis initiated from prostate cancer stem/progenitor cells. Cancer Res 72: 1878-1889, 2012.

36. Wang ZX, Lu BB, Wang H, Cheng ZX and Yin YM: MicroRNA-21 modulates chemosensitivity of breast cancer cells to doxorubicin by targeting PTEN. Arch Med Res 42: 281-290, 2011.

37. Ma F, Zhang J, Zhong L, Wang L, Liu Y, Wang Y, Peng L and Guo B: Upregulated microRNA-301a in breast cancer promotes tumor metastasis by targeting PTEN and activating $\mathrm{Wnt} / \beta$-catenin signaling. Gene 535: 191-197, 2014. 